ISSUES IN CLINICAL NURSING

\title{
Newly qualified Irish nurses' interpretation of their preparation and experiences of registration
}

\author{
Mary Mooney MSc, RGN, RM, RNT, H Dip \\ School of Nursing and Midwifery, Trinity College, Dublin, Ireland
}

Submitted for publication: 9 August 2005

Accepted for publication: 18 March 2006

\author{
Correspondence: \\ Mary Mooney \\ School of Nursing and Midwifery \\ University of Dublin \\ Trinity College \\ 24 D'Olier Street \\ Dublin 2 \\ Ireland \\ Telephone: +353-1-608-2692 \\ E-mail: mooneyma@tcd.ie
}

MOONEY M (2007) Journal of Clinical Nursing 16, 1610-1617

Newly qualified Irish nurses' interpretation of their preparation and experiences of registration

Aims and objectives. The aim of this paper is to report on the insights of newly qualified Irish nurses into their preparation for registration as general nurses and to develop insights into the postregistration experience.

Background. Nurse education in Ireland has undergone much reform over the past decade. These changes include the introduction of supernumerary status for nursing students and the formation of links with institutes of higher education. No Irish literature was found on this subject.

Method. Individual semi-structured, in-depth interviews were held with 12 newly registered nurses, from two cohorts, within 10 months of qualification. A grounded theory approach was adopted and content analysis employed to analyse the data.

Results. Two categories, entitled Learning the Ropes and The Metamorphosis emerged from the analysis of data. Within each of these categories there were two subcategories. All respondents reported that since qualification, they had become increasingly conscious of their isolation and unmet needs as nursing students. Postregistration, they enjoyed their increased status and widespread recognition by others.

Conclusions. This study details how improvements can be made at clinical level to assist the preparation of nursing students for registration. The positive aspects of registration are revealed through descriptions of comparisons of pre- and postregistration experiences, while the shortcomings of the journey to registration are described.

Relevance to clinical practice. Pre-registration nurses have unmet clinical needs which, if fulfilled, would benefit them post-registration. Good ward morale is elementary for student learning and enhances the post-registration experience. Registered nurses are highly conscious of their altered status. These findings are pertinent to clinicians and educationalists as they prepare nursing students for practice.

Key words: clinical learning environment, newly qualified nurses, nurses, nursing students, preparation for practice, supernumerary 


\section{Introduction and background to study}

The concept of supernumerary student status was introduced in Ireland in 1994. Therefore, It is just a decade since newly qualified Irish nurses had supernumerary student status. Prior to 1994, within the Irish traditional nursing education system, the student nurse occupied a dual role, as both worker and learner. Clinical learning was often incidental and limited to intuitive experiences, as students learned from each other and from care attendants (Treacy 1991, Robbins 2000). Changes to the educational system were implemented after concerns were raised regarding the lack of structured clinical teaching and the inadequate preparation of nurses for postregistration practice (An Bord Altranais 1994, Commission on Nursing 1998).

The strong, negative feelings voiced by undergraduate nurses (White et al. 1994, Wilson-Barnett et al. 1995, May \& Veitch 1998, Calman et al. 2002) and newly qualified nurses (Kramer 1974, Macleod-Clark et al. 1997, Ross \& Clifford 2002) supported a decision to conduct research into this area, which was previously unexplored from the perspective of the newly qualified nurse in Ireland. Such research is fundamental to the development of knowledge into the effectiveness of the current preparation of Irish nursing students for practice, as all nursing students today have supernumerary status.

The impact of the clinical learning environment on the development, education and experiences of nursing students has been extensively researched (Ogier 1981, Dunn \& Hansford 1997, Savage 1998, 1999, McCarthy 2000). A positive correlation between high-quality clinical learning experiences and preparation for clinical practice has been identified (Reid-Searl \& Dwyer 2005). The clinical learning environment is a powerful catalyst that influences students' learning and should prepare them for the transition to becoming a registered nurse. However, many nurses report that they feel inadequately prepared for the responsibilities and role of a registered nurse (Jasper 1996, Amos 2001, Whitehead 2001).

A study by Hyde and Brady (2002) identified that registered nurses considered supernumerary students to be observers as opposed to learners of practice. Findings such as these may have implications for student learning and development as the misinterpretation, by registered nurses, of the term supernumerary status could result in students being omitted from active participation in patient care; an omission such as this could have a negative impact on their ability to perform as a registered nurse.

The relevance of the need to explore the effectiveness of the preparation of Irish nurses for practice has thus been identified. The aim of this paper is to report on the insights of newly qualified Irish nurses into their preparation for registration as general nurses and to develop insights into the post-registration experience.

\section{Method}

A qualitative methodology was adopted. A descriptive, exploratory study using a grounded theory approach was carried out. Grounded theory is useful for situations that have not been previously studied or where existing research has left deficits in knowledge (Schreiber \& Stern 2001). With these considerations in mind this approach was considered suitable for the exploration of how newly qualified nurses perceived their preparation for registration and their postregistration experiences in Ireland.

\section{Location}

This study was carried out in an Irish acute general hospital setting.

\section{Sample}

To proceed with the study, formal permission was sought and permission granted from the appropriate gatekeepers. The Human Resources department furnished the researcher with a list of potential participants, as requested by the Director of Nursing. From the list, a purposive sample was chosen, that is the selection of participants by the researcher who are considered to be good sources of information. The sample comprised two separate cohorts of newly qualified nurses, who had been supernumerary students in the research site and were employed there as registered nurses. All nurses were in the six to ten month post-qualification period.

\section{Ethical considerations}

Ethical approval was sought and granted from the Hospital Research Ethics Committee. Issues surrounding informed consent, anonymity, confidentiality, data generation and handling were considered and upheld. Before consent for participation was sought, written information about the study was provided for potential participants.

\section{Data collection and analysis}

Strauss and Corbin (1998) advocate that the researcher should facilitate a flexible and sensitive approach to data collection and become interactive in the research process. It was felt that this might be best achieved through individual 
semi-structured, in-depth interviews, which is consistent with grounded theory methods. By using this method, stories were completed, without interruption, while opportunities to explain meanings were made available.

A feature of grounded theory is the simultaneous collection, coding and analysis of data. Within this study, the only time that data generation took place in isolation from the other procedures was during the initial interview. The processes of data collection, coding, theoretical sampling and analysis were concurrent thereafter. The process of theoretical sampling necessitates sampling on the basis of emerging concepts. Sampling within each successive interview was based on the emerging concepts derived from the preceding interview. All interviews were recorded, with one exception, at the request of one participant. Notes were taken throughout all 12 interviews. The interviews were typed verbatim.

Strauss and Corbin (1998) state that the analysis process in grounded theory is both a science, in that rigor is maintained, and an art, in that creativity is required to perform the research. Data analysis began during interviews and continued throughout the transcribing process. This was assisted through the use of field notes, active listening and in-depth explorations of emerging data. At the end of each interview, the Gibbs reflective cycle, cited by Johns (2000), was used to reflect on the interviews and the emerging analyses.

Data were handled manually. Coding began with line-byline analysis and 'in vivo' codes were used at the open coding stage. Index cards were used to assist with the development of subcategories, as data were being handled manually. Data were visited and reviewed frequently until codes were refined into subcategories, from which categories were developed.

The development of main categories from subcategories is referred to as axial coding. Axial coding permitted the development of more abstract definitions and the assignment of subcategories where they appeared to appropriately fit. Strauss and Corbin (1998) emphasize the importance of this procedure by maintaining that concepts must earn their way into the data. Categories were compared to ensure that they were distinctive, exclusive of each other and inclusive of all data. A limited time frame and relatively small sample size prevented progression to selective coding.

\section{Findings}

Two categories, each with two subcategories emerged from the analysis of data and are discussed in this section. The category relating to the perceptions of nurses' preparation for registration was entitled Learning the Ropes. This category described participants' interpretation of their preparation for the role of registered nurse. For respondents to make sense of their preparation for registration, they contrasted their pre and post-registration perceptions and experiences. The indepth descriptions provide the reader with an insight into how student-learning experiences prepared participants for the transition to registration. The quality and quantity of clinical teaching had an impact on respondents' perceptions of their readiness for registration. This category is comprised of two sub-categories, Learning on the Edge and Feeling like a Shadow.

\section{Learning the Ropes}

\section{Learning on the Edge}

This subcategory describes participants' perceptions and experiences of clinical teaching and learning during their time as supernumerary students. The descriptions were of limited and selective teaching, lack of responsibility and learning only the 'basics'. These descriptions were, at times, less than desirable and depended heavily on the specific ward allocation. Participants spoke about how, as students, they were shown what registered nurses considered to be interesting. Specific unmet learning needs, which were considered fundamental to survival as a registered nurse, were identified by respondents and included learning how to order stock, write a transfer letter for a patient or organize a referral for a patient:

They [registered nurses] bring you to see big things. You'd like to see other things like how to draw up IVs or how to order things. Those are the mundane things that we were never shown.

When you qualify and on rostered [placement] you learn about the important things. Nobody really tells you but it's like you suddenly come to know [what's important]. I suppose you just follow the routine and learn the ropes.

Participants reported that they had insufficient opportunities in the clinical area to prepare for the transition to becoming a qualified nurse. These nurses reported that as supernumerary students, they felt detached and perceived that they were burdensome to registered nurses, which prompted them to work alone and avoid intrusion. This meant that they were often unaware of what was going on in the clinical area and felt unsure about the actual staff nurses' role. They likened student learning to be on the outside looking in:

Supernumerary student means that basically you are doing basic nursing care. You don't actually know what is happening and you don't know the routine. You do what you know has to be done, like observations, beds and showers. You think that's all a nurse has to do. 
When you are a supernumerary student, you could be doing anything and nobody calls you. A lot of people don't understand the purpose of being supernumerary.

The newly qualified nurses described how, as students, they yearned for diverse learning to help them to prepare for the staff nurse role. As students they often felt forgotten about and were oblivious to ward activities, despite being physically present. This may explain why participants felt uninvolved and out of touch:

For example, the staff nurse might say his drain has to come out and you'd [the student] be thinking I didn't know it had to come out. I would go and do it anyway, but I never knew it had to come out.

These stories of limited clinical involvement, inadequate teaching and insufficient supervision of students, are typical of those told by all 12 participants interviewed. The stories were told retrospectively, which strengthens the findings, as these newly qualified nurses considered possible reasons for their knowledge deficits in some vital areas of clinical practice. Respondents were asked whether they felt that their experiences as students assisted them in their student facilitation role as registered nurses. All participants felt that they made greater efforts to facilitate, teach and include students, based on their own experiences. However, the majority also acknowledged that registration provided them with new insights into the reasons why staff nurses exclude students. While the exclusion of students was not condoned by participants, neither was it perceived any longer to be a failing on the part of registered nurses.

\section{Feeling like a Shadow}

This subcategory details descriptions of how respondents felt in the way, disengaged and sometimes ignored as supernumerary students in the clinical area. Throughout their placements as supernumerary students, participants reported unpleasant memories of seeking occupation and working alone for long periods in the wards, so as to appear busy and give qualified nurses a break from their very presence. Some participants discussed overhearing registered nurses complain about having to supervise students:

As a supernumerary student I was always like a shadow following whoever [the preceptor] I was latched onto that day. I felt in the way a lot of the time.

Participants often sensed that they were asked to do things just to be kept busy. They described how if they heard an up to date report, it was because of good fortune that they were with the staff nurse and happened to overhear the information:
I wasn't involved as a student. I used to feel like I was annoying the nurse by being constantly around her.

It would put you off going in [to work] if you know that you are going to be standing around and doing nothing and nobody asking you if you want to do things.

This category entitled Learning the Ropes, describes participants' preparation for the staff nurse role. All 12 participants reiterated that opportunities for student learning varied, depending on the ward allocation and the morale and teaching ethos on that ward. The descriptions of negativity associated with clinical teaching and learning in many areas are a stark contrast from the guidelines provided by An Bord Altranais (2003) (The Irish Nursing Board).

Throughout the interviews, the newly qualified nurses articulated the distinctive contrast of status between being a supernumerary student and being a qualified nurse:

Just that you are more valued now [as a registered nurse] and it matters that you are there and that you are doing what you are supposed to do. That is a big difference from being a student.

It's amazing too, the transition [pause] the way you are completely different once you get into the blue [colour of staff nurse uniform]

This demonstrated the need for participants to contextualize their learning experiences, both before and after qualification. This comparison was important, as the level of preparation required for registration and the level actually attained had to be evaluated to place it in context:

Now [as a registered nurse] you have more confidence in yourself. You don't realise it but that is what you are doing, you are giving off more confidence. As a student you might not have felt that confidence because you felt afraid of what they [patients] would ask you but now like, you have more confidence.

The category that describes the post-registration experience is discussed in the forthcoming section and is entitled The Metamorphosis.

\section{The Metamorphosis}

The category described the onset of change brought about by the transition to becoming a registered nurse. The newly qualified nurses described feelings of importance and enjoyment that were associated with being qualified. These positive feelings were contrasted with the negative feelings experienced as undergraduate nurses. Within this category participants discussed changed reactions towards them by others and dramatic differences within themselves. The onset 
of The Metamorphosis was perceived to be linked exclusively with the move from wearing a student uniform to wearing a staff nurse uniform. It seemed that the transitional experiences hinged on the physical change of uniform. The two subcategories that depict these changes are entitled Becoming Visible and A New Awakening.

\section{Becoming Visible}

Participants reported feelings of recognition, acknowledgement and acceptance after they qualified. All 12 newly qualified nurses discussed how they felt physically different in their staff nurse uniforms and perceived that they had suddenly become visible to others. One nurse described how she felt totally invisible as a student. She had been working on the same ward for the previous three months as a student, yet after she had qualified a consultant asked where she had come from:

You are more involved because you are wearing the blue. As soon as we put on the uniforms, it made a huge difference.

Becoming visible was evident from the ways in which people who previously ignored them now acknowledged their presence:

Because I am wearing the blue, doctors actually talk to you more. They start talking to you, full stop. They [doctors] never did before.

The attitudes of ward managers and multi-disciplinary team members changed towards participants when they became registered nurses. Respondents perceived that they were now an integral part of the team and that their presence on the ward was valued. These feelings arose from new experiences, such as being involved, being trusted to make decisions and being asked their opinions. This was something they had not experienced as supernumerary students:

Sisters involve you more now. Definitely people's perceptions of you change when you get into the blue uniform. You feel like part of the team and everybody knows your name.

In addition, the nurses found that the patients and relatives showed changed reactions towards them, which led to enhanced nurse-patient relationships. The increased recognition, involvement and acknowledgement of presence, as registered nurses, reinforced the extent of isolation, exclusion and dependence as pre-registered nurses.

\section{A New Awakening}

This subcategory described the changes that occurred within participants themselves, after they qualified. These changes included a renewed interest in learning, improved interpersonal skills and somewhat improved levels of confidence, selfesteem and assertiveness, all of which they perceived to be associated with wearing the staff nurse uniform. Participants believed that skills of assertion were now necessary as they were responsible nurses on whom patients relied. The newly qualified nurses demonstrated an ability to empathize with students and appreciated their dilemma in relation to the deprivation of sound clinical teaching and involvement. They developed insights into the disparity between staff nurses and students:

It was only when I qualified that I understood what was happening. As a student, you might think that the staff nurse was not bothering with you, but now I know that sometimes they [staff nurses] just don't have the time. As a student you don't realise that. You might give a bit more lee-way [towards the qualified nurses] if you knew that they were busy.

Narrations such as these illuminate the need for improvements in communication between registered nurses and students. The nurses in this study accepted that in the main, staff nurses did not intentionally dismiss students' learning needs. However the interaction between the two was deficient in terms of mutual understanding and communication.

The newly qualified nurses recognized the importance of student involvement and teaching. They felt guilty if they spent insufficient time with students. Those who worked with students established an interest in teaching. Most of those interviewed spoke of interest in further professional development and were interested to learn more about various conditions, so that they could inform students and provide high-quality care. Some felt that the more senior you become the less interest you have in teaching and learning. This seems ironic, as more senior nurses tend to have greater experience. Some of the nurses felt that apathy was intrinsically linked with seniority:

The older you [staff nurses] get the less interest you seem to have. Maybe it's because you get burned out...I don't want to become like them...

This category, The Metamorphosis details the descriptions of change and insights brought about as a result of registration as a general nurse. Participants perceived themselves to be different and became visible to those who had failed to notice them in the past. They felt acknowledged, valued and had an increased status. Their renewed sense of confidence, self-esteem and assertiveness assisted them in adapting to their role as Registered General Nurses. 


\section{Discussion}

The findings of this research indicate that nursing students can feel obstructive, burdensome and a nuisance to registered nurses. Published research (Twinn \& Davies 1996, Hyde \& Brady 2002) indicates that registered nurses can be unenthusiastic and insufficiently prepared for their clinical supervision role. Consequently, students may interpret negative body language and behaviour from those with whom they work. Ward managers and qualified nurses interviewed by Twinn and Davies (1996) felt that they deserved something in return for the additional workload of clinical supervision of supernumerary students. Doubtless, feelings such as these by registered nurses, communicate clear messages of rejection to supernumerary students, who in turn learn to avoid problems.

An Bord Altranais (2003) advocate that a quality learning environment is influenced by several factors including good communication and supportive relationships between registered nurses and students, team spirit and acceptance of the student as learner. The provision of such guidelines, together with the necessary education, will assist registered nurses in their teaching role and help ameliorate the identified problems associated with poor preparation of supernumerary nursing students for the role of registered nurse. Melia (1987) used the analogy of nursing in the dark to depict the situation described in this study, where there is a deficit of information given to students about patients. Findings by Bakalis and Watson (2005) indicated that registered nurses working in medical and surgical areas did not mentor nursing students in clinical practice. Failure to supervise and assist nursing students at clinical level could impact negatively on their post-registration abilities and decision-making skills. For many years now it has been established that the ward environment and registered nurses determine the learning opportunities and experiences of students (Treacy 1989, Field 2004) and influence their preparation for the role of registered nurse.

It has been postulated that the term supernumerary student confused registered nurses (White et al. 1994, Joyce 1999, Walsh \& Jones 2005). This however, could have potentially serious consequences if registered nurses undervalue nursing students' learning roles (Hyde \& Brady 2002). Findings such as these have implications for health service provider stakeholders if supernumerary students are being given insufficient opportunities to prepare for the transition to becoming a qualified nurse and to develop insights into the professional nursing role.

Researchers (Twinn \& Davies 1996, May \& Veitch 1998, Joyce 1999) contend that problems identified by students and registered nurses result from inadequate preparation of registered nurses for the role of the supernumerary student. Joyce (1999) interviewed 31 nursing students about their supernumerary learning experiences. The findings reflected those of this study in that the students did not feel that they were part of the multidisciplinary team. Some spent time studying on the wards, while others were reported to have fallen asleep while on duty. Participants in this study echoed those sentiments through descriptions of spending time making beds and seeking occupation in the clinical area. The literature (Joyce 1999, Hyde \& Brady 2002) suggests that staff nurses are confused about how much students are permitted to do and consequently, supernumerary students are relatively uninvolved and given little, if any, responsibility.

In contrast with the descriptions of the time spent as supernumerary students, the participants felt that as newly qualified nurses, they had moved to a higher status. The wearing of the staff nurse uniform accounted for the changes described. By wearing the uniform, respondents felt acknowledged and accepted. Bradby (1990) interviewed nurses who highlighted that there was meaningful significance associated with wearing a uniform in nursing. Tradewell (1996) suggested however that the feeling of becoming a nurse was associated with both working the same shifts and wearing the same uniform as staff nurses.

Researchers (Bradby 1990, Holland 1999) identified the transition of nursing students into the occupational role of nurse and identified several rites of passage. The negotiation of a status passage in nursing is eased by the development of a firm professional identity (Bradby 1990), which is linked with professional socialization. Participants in the current study felt that their sense of belonging was linked with the experience of becoming a registered nurse. This feeling of belonging was not encountered prior to registration.

Following registration, participants were eager to stay on wards where they would be identified as newly qualified nurses. Respondents considered that this was important for positive role transition experiences. Kramer (1974) identified that group cohesion and support help alleviate the helplessness and loneliness associated with the transition to becoming a registered nurse. Acceptance and support of nurses into the community of practice contributes to the development of nurses' professional identities (Lewis 1998, Winter-Collins \& McDaniel 2000) and increases their job satisfaction (Jackson 2005). According to Lewis (1998) the social setting in which nursing takes place and the quality of the social group are key factors in developing a nursing identity. An auspicious environment of inclusion and acknowledgement should therefore be made available to nursing students as well as registered nurses. 
Respondents linked their improved relationships with the multidisciplinary team, particularly with doctors, with the transition to becoming a qualified nurse. Stein et al. (1990) carried out an evaluation of the relationship between doctors and nurses and concluded that the relationship between multidisciplinary team members has improved over the past two decades. The perceived improvements in team relationships may have stemmed from participants' increased selfconfidence following registration. This possibility was not sufficiently explored in the current study but should be addressed in the future. Ohlem and Segesten (1998) suggested that professional and personal identities are interconnected and that nurses with higher self-esteem are more likely to have enhanced professional identities. However, Begley (2003) recognized that nurses generally tend to have low self-esteem. It is likely that nurses will continue to have low self-esteem if their position, as students and learners, is not embraced and fostered in a positive manner. Nursing students of today are the registered nurses of the future. Due consideration must therefore be given to their acceptance as learners in preparation for practice.

\section{Conclusion}

From the above discussion it is evident that newly qualified nurses who had supernumerary student status are faced with diverse problems post-registration. For reasons attributable to the different approaches to nursing education, traditionally trained nurses did not encounter these specific problems. While newly qualified nurses in this study enjoyed an increased status and positive acceptance of others towards them, they realized through comparison and contrast, that much time, as supernumerary students was poorly utilized in preparation for registration. The published literature (Kramer 1974, Dearmun 2000, Evans 2001) and the study described here, have identified that newly qualified nurses feel inadequately prepared for the transition to staff nurse.

An Bord Altranais (2000) suggest that a nurse acquire the skills of reflection, critical analysis, problem solving and decision-making. This challenge will not be realized if nursing students are discouraged from learning and becoming involved in clinical practice. The preparation of nursing students for the healthcare system demands and sustains interest in developing students at all levels (Ironside 2003). If nurses fail to develop the skills of reflection, assertion and critical thinking, then evidence-based practice cannot be fulfilled. This is a major implication of this study. In consideration of the foregone discussion, the researcher makes some recommendations:

- The development of ward learning objectives for nursing students in conjunction with registered nurses is recom- mended. This may provide registered nurses with a sense of ownership, which may enhance their interest in teaching and learning;

- registered nurses must be educated in relation to the meaning of the term supernumerary student and the role of the supernumerary student as learner. This concept, as was described in the background to the study, is a relatively new concept within the Irish nursing arena. There is an identifiable need for formal and structured programmes into the role of the registered nurse, as preceptor or supervisor;

- From a research perspective, it would be interesting to explore this same phenomenon with the newly qualified Bachelor of Nursing Science graduates. Their perspectives on this same issue would be interesting, considering that they have one year in a rostered capacity, which, in itself, is another status passage and a hierarchical rank above that of the supernumerary nursing student. Additional, valuable learning may take place during the rostered time.

\section{Limitations}

There are limitations within this study, which must be acknowledged. This study took place within a single research site, which may not typify other acute hospital settings. The relatively small sample of 12 renders the findings unsuitable for generalizations. In addition, the research study reflected how participants felt on a particular day, at a particular time, which implies that the findings may have varied with further or subsequent interviews. The limited time frame and sample size prevented development of selective codes and the development of a theory, grounded in the data, which is consistent with true-grounded theory. Hence for the purposes of this study, a grounded theory approach was adopted, as opposed to pure grounded theory.

\section{Contributions}

Study design: MM; data collection and analysis: MM and manuscript preparation: MM.

\section{References}

Amos D (2001) An evaluation of staff nurse role transition. Nursing Standard 16, 36-41.

An Bord Altranais (1994) The Future of Nurse Education and Training in Ireland. An Bord Altranais, Dublin.

An Bord Altranais (2000) Requirements and Standards for Nurse Registration Education Programmes, 2nd edn. An Bord Altranais, Dublin. 
An Bord Altranais (2003) Guidelines on the Key Points that may be Considered when Developing a Quality Clinical Learning Environment, 1st edn. An Bord Altranais, Dublin.

Bakalis N \& Watson R (2005) Nurses' decision-making in clinical practice. Nursing Standard 19, 33-39.

Begley C (2003) Irish nursing students' changing self-esteem and fear of negative evaluation during their pre-registration programme. Journal of Advanced Nursing 42, 390-401.

Bradby M (1990) Status passage into nursing: another view of the process of socialisation into nursing. Journal of Advanced Nursing $15,1220-1225$.

Calman L, Watson R, Norman I, Redfern S \& Murrells T (2002) Assessing practice of student nurses: methods, preparation of assessors and student views. Journal of Advanced Nurisng 38, 516-523.

Commission on Nursing (1998) A Report of the Commission on Nursing. A Blueprint for the Future. The Stationary Office, Dublin.

Dearmun AK (2000) Supporting newly qualified staff nurses: the Lecturer Practitioner contribution. Journal of Nursing Management 8, 159-165.

Dunn S \& Hansford B (1997) Undergraduate nursing students' perception of their clinical learning environment. Journal of Advanced Nursing 25, 1299-1306.

Evans K (2001) Expectations of newly qualified nurses. Nursing Standard 15, 33-38.

Field D (2004) Moving from novice to expert-the value of learning in clinical practice: a literature review. Nurse Education Today 24, 560-565.

Holland K (1999) A journey to becoming: the student nurse in transition. Journal of Advanced Nursing 29, 229-236.

Hyde A \& Brady D (2002) Staff nurses' perceptions of supernumerary status compared with rostered service for Diploma in Nursing students. Journal of Advanced Nursing 38, 624-632.

Ironside P (2003) New pedagogies for teaching thinking: the lived experience of students and teachers enacting narrative pedagogy. Journal of Nursing Education 42, 509-516.

Jackson C (2005) The experience of a good day: a phenomenological study to explain a good day as experienced by newly qualified RN. International Journal of Nursing Studies 42, 85-95.

Jasper M (1996) The first year as a staff nurse: the experiences of a first cohort of Project 2000 nurses in a demonstration district. Journal of Advanced Nursing 24, 779-790.

Johns C (2000) Becoming a Reflective Practitioner. Blackwell Science, Oxford.

Joyce P (1999) Implementing supernumerary learning in a preregistration diploma in nursing programme: an action research study. Journal of Clinical Nursing 8, 567-575.

Kramer M (1974) Reality Shock: Why Nurses Leave Nursing. Mosby, St Louis, MO.

Lewis M (1998) An examination of the role of learning environments in the construction of nursing identity. Nurse Education Today 18, 221-225.

Macleod-Clark J, Maben J \& Jones K (1997) Project 2000: perceptions of the philosophy and practice of nursing: shifting perceptions-a new practitioner? Journal of Advanced Nursing 26, 161-168.

May N \& Veitch L (1998) Working to learn and learning to work: placement experience of Project 2000 nursing students in Scotland. Nurse Education Today 18, 630-636.
McCarthy M (2000) Creating and Maintaining a Clinical Learning Environment. Discussion paper produced for the Nursing Education Forum. School of Nursing and Midwifery Studies, Trinity College, Dublin.

Melia KM (1987) Learning and Working. The Occupational Socialisation of Nurses. Tavistock, London.

Ogier M (1981) Ward sisters and their influence upon nurse learners. Nursing Times Occasion Paper 77, 41-43.

Ohlem J \& Segesten K (1998) The professional identity of the nurse: concept analysis and development. Journal of Advanced Nursing 28, 720-727.

Reid-Searl K \& Dwyer T (2005) Clinical placements for undergraduate nursing students: an educators' guide. Australian Nursing Journal 12, 21-24.

Robbins J (2000) Nursing and Midwifery in Ireland in the Twentieth Century. An Bord Altranais, Dublin.

Ross H \& Clifford K (2002) Research as a catalyst for change: the transition from student to Registered Nurse. Journal of Clinical Nursing 11, 545-553.

Savage E (1998) The ward learning environment for student nurses: a study to determine the influence of staff nurses. Part 1 . Nursing Review 16, 82-86.

Savage E (1999) The ward learning environment for student nurses: a study to determine the influence of staff nurses. Part 2. Nursing Review 17, 57-63.

Schreiber RS \& Stern PN (2001) Using Grounded Theory in Nursing. Springer Publishing, New York.

Strauss A \& Corbin J (1998) Basics of Qualitative Research: Techniques and Procedures for Developing Grounded Theory, 2nd edn. Sage Publications, London.

Stein L, Watts D \& Howell T (1990) The doctor-nurse game revisited. New England Journal of Medicine 322, 546-549.

Tradewell G (1996) Rites of passage: adaptation of nursing graduates to a hospital setting. Journal of Nursing Staff Development 12, 183-189.

Treacy M (1989) Gender prescription in nurse training: its effects on health care provision. Recent Advances in Nursing 25, 70-91.

Treacy M (1991) Nurse education vs. nurse training. Nursing Review 9, 15-19.

Twinn S \& Davies S (1996) The supervision of Project 2000 students in the clinical setting: issues and implications for practitioners. Journal of Clinical Nursing 5, 177-183.

Walsh P \& Jones K (2005) An exploration of tripartite collaboration in developing a strategic approach to the facilitation of practice learning. Nurse Education in Practice 5, 49-57.

White E, Riley E, Davies S \& Twinn S (1994) A Detailed Study of the Relationship between Teaching, Support, Supervision and Role Modelling in Clinical Areas, Within the Context of the Project 2000 Courses. English National Board for Nursing, Midwifery and Health Visiting, London.

Whitehead J (2001) Newly qualified staff nurses' perceptions of the role transition. British Journal of Nursing 10, 330-339.

Wilson-Barnett J, Butterworth T, White E, Twinn S, Davies S \& Riley L (1995) Clinical support and the project 2000 nursing student: factors influencing process. Journal of Advanced Nursing 21, 1152-1158.

Winter-Collins A \& McDaniel A (2000) Sense of belonging and new graduate job satisfaction. Journal for Nurses in Staff Development 16, 103-111. 